\title{
Experiencias de licenciamiento de derechos intelectuales y sus efectos en el medio bibliotecario
}

\author{
Intellectual property rights licensing expericences and their effects in libraries
}

\author{
Ricardo Villegas Tovar (1), Juan Carlos Marcos Recio (2), \\ Juan Miguel SÁNCHEZ VIGIL (3), María OLIVERA ZALDUA (4)
}

(1) Biblioteca del área de Cs. Sociales Económico Administrativas. Benemérita Universidad Autónoma de Puebla. Av. 22 Sur y Av. San Claudio S/N Ciudad Universitaria. Col. Jardines de San Manuel. CP 72550 Puebla-México, ricardo.villegas@correo.buap.mx (2) Sección Departamental de Biblioteconomía y Documentación. Facultad de Ciencias de la Información de la Universidad Complutense de Madrid. Av. Ciudad Universitaria S/N 28040. Madrid-España jmarcos@ccinf.ucm.es (3) Departamento de Biblioteconomía y Documentación. Facultad de Documentación de la Universidad Complutense de Madrid. C/ Santísima Trinidad, 37. 28010 Madrid-España jmvigil@ccinf.ucm.es (4) molivera@pdi.ucm.es

\begin{abstract}
Resumen
Se analizan las posibilidades de transferencia de uso de las marcas registradas para promover productos distintos a aquellos que originalmente protege la marca, esto a partir de explicar la disponibilidad de negociación que permiten los esquemas de propiedad intelectual nacionales e internacionales. Igualmente, se analizan los diferentes tipos de licenciamiento existentes en el rubro de los derechos de autor. Con el antecedente del licenciamiento de marcas y de derechos de autor, se vierten comentarios sobre la posibilidad de ampliar los esquemas de licenciamiento a favor de las bibliotecas para la creación de obras derivadas tales como antologías virtuales y bibliotecas digitales, entre otros.
\end{abstract}

Palabras clave: Licenciamiento. Marcas registradas. Derechos de autor. Bibliotecas.

\section{Introducción}

Los tiempos de la Web 2.0 son especialmente propicios al uso de las marcas y de los contenidos electrónicos. La sociedad actual vive ya plenamente conectada y pendiente del valor de unas y otros. Recientemente, los medios de comunicación se hacían eco de esta noticia: "Apple ha superado a Google y se ha convertido en la marca mundial de más valor, según un análisis de Millward Brown, filial de la empresa publicitaria WPP" (EFE, 2011). Esta posición se debe, principalmente, al éxito del iPad y del móvil iPhone tan querido por muchos consumidores. Además, los primeros puestos de la lista de BrandZ los ocupan empresas del sector de la tecnología: después de Apple y Google figuran IBM, Microsoft, AT\&T y China Mobile.

¿Cómo hemos de interpretar estos datos? ¿Qué relación tiene la tecnología en el uso de las bibliotecas? ¿Cómo han de actuar los bibliote-

\begin{abstract}
The possibilities for using trademarks in order to promote different products from those that have usually been protected by a brand is considered. First, the trading schemes allowed by the national and international intellectual property laws are analyzed. Also, the different types of current copyright licensing schemes are studied. With the precedents of licensing of trademarks and copyrights, the possibility of extending licensing to libraries for creating derivative works, such as virtual anthologies and digital libraries, among others, are discussed.
\end{abstract}

Keywords: Licensing. Trademarks. Copyright. Librarianship.

carios a la hora de licenciar contenidos? No siempre hay propuestas claras para aplicarlas en una biblioteca o centro de documentación, pero es significativo el dato de que una gran parte de los usuarios que acuden a las bibliotecas vienen ya provistos de actualizados sistemas de comunicación y consulta. Además, ya hay bibliotecas que tienen en su servicio de préstamos libros electrónicos de un determinado producto que presenta unas condiciones especiales.

Por tanto, nadie duda de la importancia que tienen en la actualidad los medios electrónicos. Desde los que prueban las versiones beta y se anticipan a cualquier novedad, hasta los que prefieren esperar para ver cómo funciona, pasando por las que son impuestas por la publicidad; todas ellas, atraen la mirada, el uso y el servicio que demandan los consumidores. También los lectores y usuarios de una biblioteca. 
Este trabajo tiene por objeto identificar cómo se licencian las marcas y cuál es el actuar paralelo del licenciamiento de obras literarias, para finalmente exponer las situaciones que atañen a las bibliotecas.

\section{Creatividad y propiedad intelectual}

El nacimiento de la propiedad intelectual como rama del derecho se da en tiempos no tan lejanos en comparación con el tiempo que tiene de existir su objeto de protección, es decir, los bienes intelectuales producto de la actividad creativa de los individuos. La reproducción en serie de las obras literarias a partir de la invención de la imprenta o las innovaciones tecnológicas que simbolizan a la revolución industrial son momentos históricos que denotan algunos de los antecedentes de esta rama jurídica. En uno y otro caso, la protección que apelaban los interesados de entonces tenía un doble motivo: el reconocimiento moral sobre la paternidad de la obra o invento y una retribución económica por la utilización pública del bien en cuestión. Previo a la reproducción y utilización masiva de estos bienes no existía un esquema legal que los protegiera, no como ahora lo concebimos. Por tanto se podría decir que la aparición de un mercado amplio que consumiera las obras intelectuales obligó a la creación de normas que regularan su aprovechamiento, buscando generar entre productores y consumidores un justo esquema de compensación.

No son pocas las personas que se han cuestionado si la desaparición de la propiedad intelectual denostaría la producción de bienes intelectuales. ¿Se dejarían de pintar cuadros? ¿Se dejarían de escribir novelas? Seguramente no. La historia misma nos demuestra que la expresión por medio de técnicas variadas es una necesidad humana que se registra desde la antigüedad en ejemplos tales como las pinturas rupestres de Altamira o las pirámides egipcias. Pero también es cierto que la desaparición de la propiedad intelectual indudablemente afectaría el ánimo de muchos autores o inventores quienes al verse desprotegidos evitarían dar a conocer el resultado de sus trabajos.

De tal suerte, la propiedad intelectual se convierte en una herramienta de desarrollo social que da certeza jurídica a quienes deseen invertir su inventiva y recursos para generar una infinidad de bienes y servicios o para aquellos quienes por medio de su creatividad expresen sus sentimientos de manera original para agradar a los sentidos. Más aún, la propiedad intelectual igualmente protege a los consumidores de estos bienes innovadores o artísticos, ofreciendo ele- mentos legales que promuevan la accesibilidad de los mismos, deviniendo en la creación de un ciclo virtuoso que se traduce en el respeto que merecen los creadores que mañana serán consumidores para regresar en breve a su posición inicial.

\section{Los signos distintivos}

La importancia de diferenciar a un producto de otro a partir de su calidad, precio u otras características se remonta a los años en que la industrialización de la economía basada en la libre competencia se posicionó como uno de los esquemas de generación de riqueza. Desde entonces, la propiedad intelectual ha creado una serie de figuras jurídicas denominadas en su conjunto como signos distintivos. Estos enmarcan la protección a los aportes de identificación que asigne el productor a su producto. De esta forma, las palabras, las letras y numerales, los colores, las formas tridimensionales, los signos audibles y hasta los olores pueden ser susceptibles de protección si por su disposición permiten al consumidor identificar al productor y marcar la diferencia del bien entre otros del mismo tipo que estén disponibles en el mercado.

Dependiendo de la legislación nacional aplicable se tendrán las figuras que conforman al grupo de los signos distintivos. Sin embargo, el común denominador es el de la marca, entendida, según el artículo 4.1 de la ley en la materia como "todo signo susceptible de representación gráfica que sirva para distinguir en el mercado los productos o servicios de una empresa de los de otras" (España, Ley de marcas, 2001). Las marcas para poder ser utilizadas como tal deben estar previamente registradas en la oficina nacional de propiedad industrial respectiva y para ello es necesario cumplir con algunos elementos de forma y fondo.

De entre los de forma resalta el relativo al registro de la marca bajo las indicaciones de la "Clasificación Internacional de Productos y Servicios" establecida en virtud del arreglo de Niza. Éste es un tratado internacional administrado por la Organización Mundial de la Propiedad Intelectual (OMPI) que indica la existencia de un esquema de clasificación de las marcas en función de los bienes o servicios a comercializar. En su novena edición establece 34 clases para productos y 11 para servicios. Aquella persona física o jurídica que registre una marca estará obligada a indicar en qué clase o clases deseará registrar su marca y en consecuencia estará legitimado para comercializar el producto en esos rubros. Ejemplo de esto se tiene con la marca Dell que se encuentra registrada en la 
Oficina Española de Patentes y Marcas bajo la clase 09 relativa a "Aparatos eléctricos y científicos" y que permite a su titular comercializar equipos de cómputo y otros similares. Al no registrarse en otra clase se admite que otras personas registren la misma marca pero para otro tipo de bienes que no compitan con el inicial. Siguiendo con el ejemplo anterior se tiene que la marca Dell también se ha otorgado en España para comercializar vestidos (clase 25) y servicios de seguros y servicios financieros (clase 36). La OEPM dispone de un localizador de marcas en Internet para saber si ya está registrada o no: http://www.oepm.es/Localiza dor/homeLocalizador.jsp y se puede buscar por denominación y por clase de Viena (elementos figurativos).

El registro de la marca otorga a su titular el derecho de utilizarla con carácter exclusivo por un lapso de diez años, tanto en México como en España, con la posibilidad de renovar el registro en tantas ocasiones como se desee e igualmente, oponerse judicialmente contra quien la utilice ilegítimamente. Además de estos derechos, al titular de la marca le asisten los de transferencia, los de cesión o licencia de uso de la misma, y con estos se vislumbra el abanico de facultades que otorga la Propiedad Industrial para generar cuadros amplios de negociación, ya que estas concesiones pueden también ser por tiempo determinado o indeterminado, de manera onerosa o gratuita y de forma exclusiva o no.

\begin{tabular}{llll}
\hline \multicolumn{1}{c}{2009} & & \multicolumn{1}{c}{2010} \\
\hline 1 & Coca-Cola $\$ 68,734$ & 1 & Coca-Cola $\$ 70,452$ \\
\hline 2 & IBM $\$ 60,211$ & 2 & IBM $\$ 64,727$ \\
\hline 3 & Microsoft $\$ 56,647$ & 3 & Microsoft $\$ 60,895$ \\
\hline 4 & GE $\$ 47,777$ & 4 & Google $\$ 43,557$ \\
\hline 5 & Nokia $\$ 34,864$ & 5 & GE $\$ 42,808$ \\
\hline 6 & McDonald's & 6 & $\begin{array}{l}\text { McDonald's } \\
\text { \$32,275 }\end{array}$ \\
\hline 7 & Google $\$ 31,980$ & 7 & Intel $\$ 32,015$ \\
\hline 8 & Toyota $\$ 31,330$ & 8 & Nokia $\$ 29,495$ \\
\hline 9 & Intel $\$ 30,636$ & 9 & Disney $\$ 28,731$ \\
\hline 10 & Disney $\$ 28,447$ & 10 & HP $\$ 26,867$ \\
\hline
\end{tabular}

Tabla I. Valor económico de las marcas

\subsection{Valor de la marca en el mercado}

Las marcas no son solo el elemento principal de identificación del productor, sino que a partir de un proceso de valoración de intangibles es po- sible identificar el costo de la marca per se. Ejemplo de esto se da con la metodología de valuación de marcas que lleva a cabo periódicamente la empresa Interbranding y que contempla tres criterios: el desempeño financiero de los productos o servicios comercializados bajo la marca, el rol de la marca en el proceso de decisión de compra y la fortaleza de la misma, es decir, el nivel de reconocimiento de la marca por el consumidor (Interbranding, 2010). A partir de la aplicación de estos criterios es que han desarrollado un seguimiento anual del comportamiento económico de las marcas medida en millones de dólares americanos como se muestra en la tabla I.

\subsection{La publicidad y las marcas}

A tenor de la relación estrecha que existe entre publicidad y marcas, nadie diría en la actualidad que una marca no puede vivir sin la publicidad, aunque haya raras excepciones como es el caso español de Zara que, gracias a la publicidad "boca a boca" y una excelente distribución que permite a sus consumidores disponer de nuevos productos en cortos espacios de tiempo, ha conquistado el corazón y el bolsillo de sus clientes.

La mayoría de los publicitarios creen en las marcas. Es más, se sienten "constructores de marcas" como afirma con frecuencia uno de los grandes publicitarios españoles, Luis Bassat. (Bassat, 1994). Sin ellas, la industria publicitaria no sería el apoyo y el complemento ideal para las empresas.

Pues bien, mientras que un fabricante crea su producto, lo dota de una serie de características propias, una imagen con su apoyo visual y un logotipo que refuerza la comunicación, la publicidad se ofrece como el movimiento transformador de ese producto en una marca, en una propuesta que el consumidor desea comprar. Ese "Lovemarks" en palabras de Kevin Roberts, de la agencia Saatchi \& Saatchi, es la unión entre el consumidor y lo que representan algunas marcas que han conseguido seducir al comprador (Roberts, 2005).

La publicidad está para construir imagen de marca, para hacer que cada producto sea atractivo para el consumidor, para que se posicione en su mente y termine por comprar ese y no otro producto. Por este motivo, publicidad y marcas se complementan entre sí y cuando un producto no logra captar la atención del consumidor es la publicidad la que ha de dar ese paso. Pero no sólo hace el esfuerzo para dar a conocer la marca, la publicidad llega más lejos, pues crea un entorno favorable a su marca. 
Esa asociación entre publicidad y marcas tiene un doble objetivo, tal y como se explica en Publicidadweb (2011):

La primera es que el público conozca esa asociación entre el producto y la publicidad, con este fin se realizan todas las acciones de comunicación... y la segunda que el producto responda a lo que promete la marca.

No siempre se cumplen, sobre todo la segunda, de ahí que algunas marcas terminen por desaparecer, pues lo que prometieron no se ajusta a la realidad del producto. $Y$ eso para una marca es peligroso, pues en la actualidad los consumidores tienen más información para comparar una con otra.

Y en las bibliotecas ¿cuál es la relación entre la marca y la publicidad? Si se toma como referencia una institución pública hay que pensar siempre en el usuario/lector, destinatario principal del trabajo bibliotecario. La cultura también se puede comercializar, pero no es esa la principal acometida de estas instituciones. Aquí habría que distinguir una doble función:

1. La imagen de marca de la institución. Crearla, mantenerla y actualizarla, añadiendo los nuevos productos y servicios que se ofrecen, pensando en mejorar cada día.

2. La comunicación que se hace de cada una de esas actividades. $Y$ aquí la publicidad puede ayudar en el proceso de comunicación, bien creando campañas específicas o dotando de alguna propuesta comunicativa dentro de las campañas generales de la biblioteca.

Por último, la publicidad cuando trabaja para las marcas está creando una imagen positiva en la mente del consumidor. Le pide que actúe en tres frentes: a) atención, ya que cada vez hay más información y más anuncios compitiendo entre ellos; b) relación, para que el consumidor sea capaz de relacionar las ventajas de esa marca con sus necesidades y c) recuerdo, para que siga creyendo en esa marca, para que compre ese producto y para que tenga siempre una buena imagen de la misma.

\subsection{El licenciamiento de marcas: generalidades y casos de éxito}

De entre las facultades que tiene el titular de una marca se encuentra el derecho de conceder a terceras personas la autorización o licencia de uso de la marca. Esta facultad deriva en una cantidad de aplicaciones como puede ser el hecho que un producto elaborado en un país pueda igualmente ser producido y comercializado en otro con las mismas características.
Ejemplo de esto se da con el periódico El País que diariamente es impreso y distribuido en México con las especificaciones de sus propietarios en España.

El contrato de licencia de uso de marca es un acuerdo en el que el licenciador, en su carácter de titular de una marca, concede a un licenciatario la autorización suficiente para que con base a ciertas especificaciones se puedan elaborar y comercializar productos originalmente considerados dentro de la clase o clases registras en virtud del convenio de Niza. Más aún, es posible comercializar productos de otras clases con la marca licenciada, esto es, la utilización de una marca originalmente concebida para un producto puede ser usada para comercializar otros completamente distintos. Ejemplo de lo aquí descrito se tiene con la licencia otorgada por Disney Consumer Products a la empresa Swarovski especializada en el diseño de joyería, quien con la temática de la película "Pirates of the Caribbean: on stranger tide" ha desarrollado una colección de anillos, aretes, brazaletes y colleras que pudieron ser adquiridos con semanas de antelación al estreno en salas de la película (Disney, 2011).

David Herrera comenta a este respecto: "el otorgamiento de licencias por el uso de una marca representa una oportunidad para obtener ingresos adicionales a bajo costo" (Herrera, 2010); y, para que esta premisa se cumpla, es necesaria la existencia de un acuerdo formal que le asegure al licenciador que los productos derivados cumplirán con sus estándares de calidad y las condiciones bajo las cuales son comercializados (WIPO, 2004).

Para abundar sobre las especificaciones de la negociación de una licencia, la propia OMPI propuso en el año 2000 la Recomendación conjunta relativa a las licencias de marcas que, entre otros puntos, propone los requisitos de forma que debe cumplir una licencia en el momento de ser inscrita en las oficinas de propiedad industrial que así lo contemplen.

\section{Esquemas de licenciamiento en el derecho de autor}

Las obras literarias, artísticas o científicas como objeto de protección del derecho de autor, según las contempla el artículo 10 de la Ley en la materia (España, Ley de propiedad intelectual..., 1996), no son ajenas a los procesos de licenciamiento por los que se transmiten derechos para una variedad de usos, muy al contrario. Gracias a la flexibilidad de los elementos que conforman a los denominados derechos patrimoniales, como lo son el derecho de repro- 
ducción, de distribución, de comunicación públi$\mathrm{ca}$, etc. es posible establecer una serie de negociaciones para la explotación de la obra según se acuerde en el contrato respectivo.

Las licencias que a terceras personas otorgará el titular de la obra recibirán tantos nombres como objetos tenga el propio contrato. El que destaca de entre ellos por lo que representa a los autores para la impresión y distribución de sus obras es el contrato de edición. Este contrato típico puede ser considerado como una licencia en lo general ya que el autor concede su venia al editor para que, en su nombre, se de a conocer públicamente el contenido de su obra literaria. Tan importante es este contrato que origina en el editor una serie de prerrogativas englobadas en lo que se conoce como derechos conexos o derechos vecinos.

Estos derechos, según los define el Glosario de Derecho de Autor y Derechos Conexos, se entienden como (Boytha, 1980):

Aquellos concedidos para proteger los intereses de los artistas intérpretes o ejecutantes, productores de fonogramas y organismos de radiodifusión en relación con las actividades referentes a la utilización pública de obras de autores, toda clase de representaciones de artistas o transmisión al público de acontecimientos, información y sonidos o imágenes.

A partir de esta definición es posible encuadrar a un gran conjunto de sujetos quienes se verían beneficiados de la protección de los derechos conexos y que van mucho más allá de los editores, como lo podrían ser los traductores, los guionistas que adaptan obras literarias al cine e inclusive a las cadenas televisivas o radiofónicas que invierten esfuerzos para divulgar legalmente las obras de las que no son titulares.

\subsection{Licencias no voluntarias}

En otro rubro de las licencias en el medio del derecho de autor se encuentran aquellas definidas como licencias no voluntarias. Estas contemplan aquellos casos en que el titular de los derechos de autor se ve obligado por mandato de la ley a permitir el uso de su obra para fines de interés público y bajo condiciones específicas que no vulneren radicalmente sus intereses morales y económicos. Para definir el alcance de este tipo de licencias la doctrina las divide en dos tipos: licencias obligatorias y licencias legales.

Las licencias obligatorias se conceden a los integrantes de la sociedad para que en virtud de una comprobación del interés público la autoridad competente permita la utilización de las obras sin el consentimiento del titular. De esta forma acciones tales como la traducción de obras extranjeras y la reproducción de obras no importadas al país en el que se requieren son acciones viables en función de que así lo contemple la legislación aplicable. Ricardo Antequera (2009) comenta que el solicitante de una licencia obligatoria debe demostrar el fracaso de sus diligencias para contactar al titular de los derechos y en consecuencia la imposibilidad de la negociación de los derechos. Ejemplo de lo aquí expuesto se refleja en el artículo 147 de la Ley Federal del Derecho de Autor de México que a la letra dice (1996):

Se considera de utilidad pública la publicación o traducción de obras literarias o artísticas necesarias para el adelanto de la ciencia, la cultura y la educación nacionales. Cuando no sea posible obtener el consentimiento del titular de los derechos patrimoniales correspondientes, y mediante el pago de una remuneración compensatoria, el Ejecutivo Federal, por conducto de la Secretaría de Educación Pública, de oficio o a petición de parte, podrá autorizar la publicación o traducción mencionada. Lo anterior será sin perjuicio de los tratados internacionales sobre derechos de autor y derechos conexos suscritos y aprobados por México.

La segunda división de las licencias no voluntarias se refiere a las licencias legales que tienen su origen en el artículo 9.2 del Convenio de Berna para la Protección de las Obras Literarias y Artísticas y por el cual los países que se adhieran a su texto están facultados para conceder a sus gobernados una exención de pago por el uso de las obras. En otras palabras, es el usuario final de la obra quien tendrá la responsabilidad de analizar los efectos de su uso y para esto la ley indica las circunstancias específicas que justificarán la utilización libre. El citado artículo del Convenio de Berna indica tres criterios que aplicados de manera conjunta conceden o niegan el uso de la obra: La reproducción no atentará a la explotación normal de la obra, no se causará perjuicio injustificado a los intereses legítimos del autor y será en casos especiales (Convenio de Berna, 1979).

La aplicación real de estos tres criterios estará regulada por la abundancia con la que se trate el tema en las legislaciones nacionales. De esa forma es que nacen doctrinas tales como el "uso honrado" o sus acepciones en sistemas anglosajones como es el fair use o el fair dealing. Ahora bien, la complejidad del caso no viene del entendimiento del contenido de los tres criterios, sino de su aplicación en la vida real, especialmente ante la amplia disponibilidad de dispositivos electrónicos que fácilmente podrían ayudar a transgredir estas excepciones. Para evitar esta situación muchas leyes prevén un resarcimiento por el uso extralimitado que se dé de las 
obras. De tal suerte se han definido conceptos sinónimos o complementarios como es la compensación equitativa, la remuneración por copia privada, el canon digital u otros argumentos jurídicos destinados a la recuperación económica del titular afectado del incumplimiento de los tres criterios. En el caso de México, el artículo 40 de la ley federal que regula la materia indica (1996):

Los titulares de los derechos patrimoniales de autor y de los derechos conexos podrán exigir una remuneración compensatoria por la realización de cualquier copia o reproducción hecha sin su autorización y sin estar amparada por alguna de las limitaciones previstas en los artículos 148 y 151 de la presente Ley.

En España, la disposición homóloga a la que precede va mucho más allá de la declaración de una remuneración compensatoria. Se trata del artículo 25 del Texto Refundido de la Ley de Propiedad Intelectual que bajo el título "Compensación equitativa por copia privada" detalla cómo por medio de la imposición de gravámenes a los equipos con capacidades de duplicación o almacenaje digital se recaudará el ingreso a los titulares del derecho de autor por aquellos usos que ignoran los principios de la tres criterios del Convenio de Berna. Para confirmar la facultad que el Estado español tiene para el establecimiento de los mecanismos de recaudación, el artículo 5 de la "Directiva relativa a la armonización de determinados aspectos del derecho de autor y derechos afines a los derechos de autor en la sociedad de la información", hace referencia a la compensación equitativa al indicar que los titulares de los derechos deben verse beneficiados como consecuencia de las reproducciones de sus obras.

\section{Como bien comenta Eduardo Bautista (2008),}

se han vertido ríos de tinta y se han producido innumerables debates en los medios de radiodifusión sobre las distintas posiciones que, en relación la copia privada, mantienen, de un lado titulares de derechos de propiedad intelectual y, de otro, internautas, consumidores, usuarios y asociaciones representativas de la industria de los fabricantes de soportes y equipos digitales.

Por tanto, es complicado hacer un comentario contundente desde la perspectiva bibliotecaria, ya que como suele suceder en estas circunstancias las bibliotecas se encuentran en una posición intermedia, primero como promotoras incansables del acceso a la información y segundo como promotoras del respeto a los derechos de autor.

Como se ha visto, tanto las licencias obligatorias como las legales tienen una incidencia importante en el medio bibliotecario. Aplicarlas inde- bidamente puede causar perjuicios serios a sus titulares, de ahí la importancia de su estudio serio y más aún, de su correcta aplicación.

\subsection{Las sociedades de gestión colectiva como} mediadores en el uso de las obras literarias

La gestión colectiva según la define Delia Lipszyc (1993), es:

El sistema de administración de derechos de autor y de derechos conexos por el cual sus titulares delegan en organizaciones creadas al efecto la negociación de las condiciones en que sus obras, sus prestaciones artísticas o sus aportaciones industriales serán utilizadas por los difusores y otros usuarios primarios, el otorgamiento de las respectivas autorizaciones, el control de las utilizaciones, la recaudación de las remuneraciones devengadas y su distribución o reparto entre los beneficiarios.

Para que la gestión colectiva pueda operar como tal, será vital que las legislaciones contemplen un apartado respecto a la existencia y operación de aquellas organizaciones que se encargarán de tan importante tarea, ya que como bien ha indicado Tarja Koskinen (2005), para que un sistema de derechos de autor funcione de manera correcta es necesario contar con tres pilares: una legislación adecuada, la procuración de cumplimiento de la ley y una efectiva gestión de los derechos de autor.

Es la propia Sra. Koskinen quien explica en su libro La gestión colectiva en el ámbito de la reprografía cómo las organizaciones encargadas de la recaudación por la reproducción de obras literarias deben garantizar la remuneración equitativa a los titulares de los derechos, así como facilitar a los usuarios el cumplimiento del pago compensatorio. Para ello, explica el funcionamiento de estas organizaciones a partir de la variedad de modelos existentes que, basados en licencias, permiten su operación en diferentes países.

De entre ellos resalta el caso español y el mexicano que comparten el modelo de operación de licencia colectiva voluntaria. Éste otorga a los titulares de derechos de autor la facultad de verse representados por una organización que gestione los derechos de reproducción de sus obras. Serán estas organizaciones quienes con el mandato de representación deberán echar a andar los mecanismos legales a su alcance para el cumplimiento de sus encomiendas. Por ejemplo, llegarán a acuerdos con bibliotecas o centros de fotocopiado, o podrán establecer alianzas con otras organizaciones extranjeras de gestión colectiva para extender el cobro de derechos. 
El funcionamiento del Centro Español de Derechos Reprográficos (CEDRO) es de resaltar entre las sociedades de gestión colectiva, ya que opera bajo el sistema de licencia voluntario mixto: por una parte, recauda ingresos para sus representados por la imposición legal del denominado canon digital; $y$, por otra, recauda ingresos por la vía de las propias gestiones que pueda ejecutar, como son aquellos usos fuera de lo permitido por el concepto de copia privada. Este modelo de recaudación por copia privada vinculada a un sistema de gravamen le ha permitido a CEDRO la recaudación y distribución de $€ 23,309.508$ a sus 19.275 representados (IFRRO, 2011).

El caso mexicano es distinto ya que la ley vigente en la materia no contempla la imposición del gravamen a los equipos duplicadores de las obras. Por tanto, el Centro Mexicano de Protección y Fomento a los Derechos de Autor (CEMPRO) en su calidad de sociedad de gestión colectiva solo puede obtener ingresos por la vía de las gestiones que realice según el nivel de representatividad de titulares de derechos de autor agremiados a él.

Para revertir esta situación, el 10 de diciembre de 2009 en la Cámara de Diputados mexicana se presentó una iniciativa que pretendía reformar la Ley Federal del Derecho de Autor. Buscaba establecer un esquema similar al canon digital español por el cual se obtendría una compensación ante la incorrecta aplicación de la licencia legal relativa al uso personal de las obras encuadradas en el ya comentado criterio triple. Durante los debates públicos de mayo de 2010 sobre las pretensiones de la iniciativa se argumentó que las Sociedades de Gestión Colectiva no contaban con un ordenamiento contable lo suficientemente preciso como para demostrar la justa distribución de los ingresos y por tanto se desecho la iniciativa.

\subsubsection{Licencias libres}

La gestión de las prerrogativas que conforman a los derechos de autor tampoco es una novedad, muy por el contrario. El abogado Lawrence Lessig desde finales del siglo pasado declaró en su libro "cultura libre" la facultad que tiene el autor de decidir sobre cómo su obra literaria o artística ha de ser usada, permitiéndole tomar posesión sobra esas decisiones que comúnmente el Estado tomaba de facto.

Lessig junto con otros abogados redactaron una serie de "licencias" que sin ir en contra del derecho de autor enmarcan las opciones de renuncia parcial que tiene el propio autor para administrar el abanico de facultades definidas en los alcances de los derechos morales y de explotación. De esta forma nacen los "Creative Commons" que se fundamentan en la dimisión o reivindicación de tres premisas básicas: la decisión de comercialización, la permisibilidad de crear obras derivadas y que esas obras derivadas mantengan el status quo de la original, es decir, que se mantengan bajo la misma licencia de uso libre. A estas tres premisas se suma una cuarta, la del reconocimiento moral de la autoría de la obra y que no puede ser negociada excepto que el autor quiera mantenerse en el anonimato.

Maritxell Roca confirma que las licencias Creative Commons, al igual que toda licencia de uso libre aplicable a las obras literarias o inclusive al software no son sinónimo de dominio público, ya que el autor al apegarse a estos esquemas lo que está haciendo es reservarse sus derechos, y que en consecuencia los deja a salvo para exigirlos judicialmente en caso que sean transgredidos (Roca, 2007).

Bajo la misma disponibilidad de administración es que han surgido, antes o después de los Creative Commons, otros esquemas de reserva de derechos. En Zaragoza, España, se encuentra el origen del sistema Color luris que bajo un catálogo de contratos pre-elaborados y depositados con un tercero facilitan el reconocimiento de libertades e impedimentos de uso de obras que se encuentran en la red. Se suman otros usos libres como el GNU free documentation license o el EFF open audio license que, enfocados respectivamente al software y a los archivos digitales de audio, promueven una utilización que rompe con la tradición del pago compensatorio.

La suma de estos movimientos conocidos como Open Access y que promueven el uso libre de las obras ha derivado en aplicaciones que benefician a los usuarios de la información. Así han surgido colecciones electrónicas de publicaciones periódicas que sólo existen en el medio electrónico y que sin menoscabo de su calidad de contenidos permiten el acceso. Por mencionar un solo caso se tiene el de la Public Library of Science.

Ante la presencia de este tipo de plataformas, la industria editorial de las publicaciones periódicas impresas no se ha dejado rebasar. Tan es así que ya no es extraño ubicar en versiones electrónicas de revistas científicas la disponibilidad de algunos de sus artículos en versión open access. 


\section{Experiencias de licenciamiento en el medio bibliotecario}

Toda biblioteca por el simple hecho de estar inmersa en el uso de tecnologías de información se ve obligada constantemente a trabajar con licencias, ya sea para la adquisición de un software administrador de bibliotecas (OPAC), para el acceso a un sistema de información en línea o simplemente para poner en funcionamiento los ordenadores del módulo de circulación.

Como se ha visto, las licencias son el instrumento legal que instruyen la modalidad de uso que espera el licenciador del licenciatario y por tanto comúnmente estarán escritas para favorecerle. Tan es así que es posible encontrar licencias que limitan o nulifican ciertas prerrogativas que la ley otorga a las bibliotecas. Por ejemplo, ciertas legislaciones conceden a las bibliotecas el permiso de realizar copias privadas a petición de sus usuarios. Esta facultad podría ser revocada por la licencia si así se definiera en su clausulado. Por tanto, es obligación del bibliotecario comprender las imposiciones y libertades consideradas en el clausulado y analizar si se encuentra en la posición de asumirlas u optar por rechazar la adquisición del acceso o del software.

Ejemplo de lo aquí expuesto se puede dar con el hecho de que muchos sistemas de información en línea, como son las bases de datos o las revistas electrónicas, no conceden el acceso perpetuo a sus contenidos posterior a la terminación del contrato con la biblioteca. Este es un hecho contradictorio a la filosofía de cualquier biblioteca que siempre está deseosa de preservar y difundir los contenidos de sus colecciones.

Ante los efectos de este tipo de cláusulas en las funciones básicas de cualquier biblioteca debe preverse la posibilidad de negociación de sus alcances. Para hacer contrapeso a las decisiones de los dueños de contenidos la práctica demuestra cómo el licenciamiento consorciado ha sido una poderosa herramienta de negociación, ya que no solo abarata los costos de acceso o promueve la capacitación para el uso de los sistemas, sino que también puede ser el medio para modificar cláusulas que puedan afectar el servicio bibliotecario.

Ahora bien, en la otra cara de la moneda del licenciamiento se encuentra a la biblioteca como licenciador y no como licenciatario. No son pocas las bibliotecas que con la disponibilidad de nuevas tecnologías han incursionado en el mundo editorial al crear repositorios digitales de contenidos provenientes de la literatura gris. Para la conformación legal de estos espacios virtuales será obligatorio que las bibliotecas cuenten con la autorización de uso de obras o la cesión de derechos de reproducción de cada una de las albergadas en los repositorios. Ante la importancia que comúnmente dan las bibliotecas al libre acceso a este tipo de contenidos, no es extraño ver que estos repositorios también se encuentren bajo licencias Creative Commons.

Así, las bibliotecas juegan un doble rol, el de licenciatarios para la adquisición de accesos a sistemas de información o uso de software, y el de licenciadores para permitir el uso de sus propios recursos.

\section{Conclusiones}

El presente y futuro de la propiedad intelectual no radica en los trámites de registro o en las persecuciones judiciales de cada uno de los elementos que la conforman, sino en la administración de todos esos derechos para la generación de ingresos de los propios titulares y en beneficio del consumidor. Para el caso concreto de los derechos de autor, se deberá seguir insistiendo en el establecimiento del equilibrio entre el derecho de compensación al autor y el derecho de acceso y uso de las obras literarias, artísticas y científicas. En palabras de Francis Gurry (2011), Director General de la OMPI, el futuro del derecho de autor debe estribar en la ejecución de acciones impostergables para la adaptación de esta importante rama del derecho ante las necesidades reales de los usuarios de las obras, quienes asistidos por la tecnología encuentran una diversidad de obras, pero a la vez, un impedimento de uso de ellas ante la posibilidad de incurrir en faltas legales. De tal suerte el propio Gurry propone la utilización coordinada de acciones tales como la actualización de la legislación vigente, un cambio en la cultura, la colaboración institucional y mejores modelos de negocio.

A lo largo del presente trabajo se ha intentando explicar de manera resumida los esquemas de licenciamiento de las marcas y lo relativo a los derechos de autor. En uno y otro caso queda claro cómo el abanico de facultades que otorgan las leyes a los titulares de estos derechos les permiten llegar a los acuerdos que mejor convengan a ellos y a sus contrapartes.

El medio bibliotecario no es ajeno a los procesos de licenciamiento, especialmente en el rubro de las obras literarias y las tecnologías, sin embargo, la práctica muestra que los bibliotecarios no siempre están en la posibilidad de negociar licencias, ni cuando compran software, ni cuando adquieren accesos a sistemas de infor- 
mación en línea. Esta situación los pone en desventaja, ya que si difícilmente pueden negociar una licencia, menos podrán promover una para satisfacer las siempre crecientes demandas de sus usuarios, quienes ávidos de usar las nuevas tecnologías requieren de más contenidos de mayor calidad y con una amplia accesibilidad y opciones de manipulación.

No estará por demás que los bibliotecarios conozcan más sobre la variedad de opciones que el derecho de autor otorga para el licenciamiento, mientras que los dueños de contenido deberán ubicar en los bibliotecarios a un aliado para crear obras derivadas. De esta forma, la creación de más sistemas digitales elaborados en coordinación de bibliotecarios y editores alcanzarán a los usuarios, todo siempre dentro de un marco de respeto a los derechos de autor y privilegiando el derecho de acceso a la información.

\section{Referencias}

Antequera, Ricardo (2009). Las Licencias Obligatorias como Límites a los Derechos de Propiedad Intelectual. // Re-

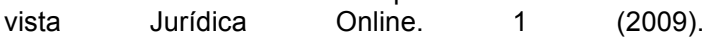
http://www.revistajuridicaonline.com/images/stories/revis tas-juridicas/propiedad-intelectual-tomo-1/1las_licencias_obligatorias.pdf (2011-05-08).

EFE (2011). Apple es la marca mundial con más valor (2011). Londres: Efe, 2011. http://www.antena3.com/noticias/tecnologia/applemarca-mundial-mas-valor_2011051400061.html (201105-30).

Bassat, Luis (1994). Entrevista con Anatxu Zabalbeascoa. // Creativity News. 13 (marzo 1994) 52.

Bautista, Eduardo (2008). La copia privada en el entorno digital: la experiencia española // Revista Iberoamericana de Derecho de Autor. ISSN 1909-6003. II: 4 (juliodiciembre 2008) 12-19.

Boytha, György; et al. (1980). Glosario de Derecho de Autor y Derechos Conexos: voz 53. Ginebra: OMPI, 1980.

Convenio de Berna para la Protección de las Obras Literarias y Artísticas (1979). París: Organización Mundial de la Propiedad Intelectual, 1979. http://www.wipo.int/export/sites/www/treaties/es/ip/berne /pdf/trtdocs_wo001.pdf (2011-05-16).

Disney consumer products press release (2011). Pirates of the Caribbean: On Stranger Tides Inspired Product Sets Sail, 2011. https://www.disneyconsumerproducts.com (2011-05-30).
España (2001). Ley de Marcas 17/2001, de 7 de Diciembre // Boletín Oficial del Estado. 8 (diciembre 2001). Madrid: Ministerio de Cultura. BOE, 2003-23093. 45579-45603. http://www.boe.es/boe/dias/2001/12/08/pdfs/A4557945603.pdf (2011-05-15).

España (1996). Ley Propiedad Intelectual 1/1996, de 12 de Abril, Texto Refundido de la Ley de Propiedad Intelectual // Boletín Oficial del Estado (22 de marzo 1996). Madrid: Ministerio de Cultura. BOE-A-1996-8930, 14369-14396.

http://www.boe.es/boe/dias/1996/04/22/pdfs/A1436914396.pdf (2011-05-15).

Gurry, Francis (2011). WIPO Director General Addresses the Future of Copyright.// WIPO. París: World Intellectual Property Organization. (2011).http://www.wipo.int/pressroom/en/articles/2011/ar ticle_0005.html (2011-05-30).

Herrera, David (2008). Regalías por uso de marca: el valor sobre la mesa // Interbrand. 2 (2008).http://www.interbrand.com/Libraries/Articles/1_Regalias.sflb.ashx (2011-05-30).

Interbranding (2010). Best global Brands 2010: Methodology. I/ Interbrand. (2010). http://www.interbrand.com/en/best-global-brands/bestglobal-brands-methodology/Overview.aspx (2011-0530)..

International Federation of Reproduction Rights Organisations (2011). CEDRO Financial Data. // IFRRO Member. (2011) http://www.ifrro.org/members/centroespa\%C3\%B1ol-de-derechos-reprogr\%C3\%A1 ficos (2011-05-30).

Koskinen, Tarja (2005). La gestión colectiva en el ámbito de la reprografía. Primera edición. OMPI-IFRRO. ISBN 92805-1406-7.

Lipszic, Delia (1993). Derechos de autor y derechos conexos. Buenos Aires: Zavalia, 1993. ISBN 950-572-240-0.

México. Ley Federal del Derecho de Autor (1996) // Diario Oficial de la Federación de México. (24 diciembre 1996). http://bnm.unam.mx/files/servicios/reprografia/Derechos Autor.pdf (2011-05-15).

Publicidadweb (2011). Publicidad y marcas. http://www.publicidadweb.ws/tipos/publicidad-ymarcas.html (2011-05-30).

Roberts, Kevin (2005). Lovemarks: the future beyond Brands. Nueva York: PowerHouse Books, 2005. ISBN 157687270X

Roca, Meritxell; Castells, Manuel (2007). Derechos de propiedad intelectual e Internet en España: Materiales para un debate informado. Barcelona: UOC, 2007. http://firgoa.usc.es/drupal/files/F-1469-1495.pdf (201105-06).

World Intellectual Property Organization (2004). WIPO Intellectual Property Handbook: Policy, Law and Use. Geneve: Wipo, 2004. ISBN 92-805-12917-7. 
